\title{
Faktor Yang Berpengaruh Terhadap Kinerja Guru Pada Sekolah Menengah Di Kota Batam
}

\author{
Dame Afrina Sihombing \\ Universitas Internasional Batam, dame@uib.ac.id
}

\begin{abstract}
ABSTRAK
Pendidikan di Indonesia kian hari semakin memprihatinkan. Pemeringkatan yang dilakuakn di ASEAN melalui Education Index oleh Human Development Reports, dengan nilai skor 0,622 dengan posisi ketujuh yang merupakan posisi Indonesia. Selain itu, data dari The Global Talent Competitiveness Index (GTCI) pada tahun 2019 bahwa Indonesia menduduki urutan ke 67 dari 125, SDM di Indonesia belum memiliki daya saing yang baik dibandingkan dengan negara lain. Populasi merupakan guru sekolah menengah di Kota Batam. Kuesioner yang disebarkan sebanyak 375 dengan penyebaran ke sekolah menengah di Kota Batam. Penelitian ini diuji dengan menggunakan SPSS. Hasil dari penelitian ini menunjukkan bahwa motivasi, kepuasan, sikap dan kinerja manajemen pengetahuan berpengaruh signifikan terhadap kinerja, sedangkan dukungan sosial tidak memiliki pengaruh terhadap kinerja. Hal ini dikarenakan kebanyakan guru jarang bertemu orang lain diluar lingkup sekolah sehingga situasi ini dianggap menjadi monoton karena hanya mengajar dan mereka menjadi kurang dalam menjalin hubungan dengan orang di luar lingkup mereka tersebut.

Kata Kunci : Motivasi Kerja; Dukungan Sosial; Kepuasan Karyawan; Perilaku; Kinerja
\end{abstract}

\begin{abstract}
Education in Indonesia is increasingly worrisome. The ranking is done in ASEAN through the Education Index by Human Development Reports, where Indonesia is on 7th position with a score of 0.62. In addition, data from the Global Talent Competitiveness Index (GTCI) in 2019 said that in the 67th order out of 125, HR in Indonesia did not have good competitiveness compared to other countries. The population of this research is secondary school teachers in Batam City. 375 questionnaires were distributed to secondary schools in Batam City. This research was tested using SPSS. The results of this study indicate that motivation, satisfaction, attitude and performance of knowledge management have a significant effect on performance, while social support has no influence on performance. This is because most teachers rarely meet other people outside the scope of the school so this situation is considered to be monotonous because they only teach and they become less in establishing relationships with people outside their scope.

Keywords: Motivation, Social Support, Satisfaction,Attitude, Performance
\end{abstract}

Naskah diterima: 27-08-2020, direvisi: 09-07-2020, diterbitkan: 01-09-2020

ISSN: 2355-0295, e-ISSN: 2549-8932 


\section{PENDAHULUAN}

Tuntutan dari perkembangan zaman saat ini sangat cepat terasa. Dahulu guru mengajar masih menggunakan papan tulis dan kapur untuk menulis serta metoda pembelajaran yang digunakan konservatif. Saat ini dengan hadirnya teknologi sebagai sarana pembelajaran yaitu komputer dan laptop, proyektor serta internet sebagai sarana pembelajaran masa kini. Semua bentuk informasi dapat ditemukan dengan cepat dan mudah. Namun, semua guru yang masih bersifat konservatif juga perlu pembimbingan dan latihan untuk menggunakan sarana pembelajaran tersebut agar tidak kalah dengan siswa yang diajarkan. Materi pembelajaran digital yang tersedia sangat banyak dan mudah untuk didapatkan namun belum semua guru dapat mengikutinya dan menggunakannya sebagai bahan pembelajaran. Dan lagi, sarana pembelajaran tadi yang seharusnya dapat digunakan untuk pembelajaran tapi ternyata hanya digunakan siswa kebanyakan untuk bermain bukan melatih cara menulis dan mengetik.

Sistem Pendidikan di Indonesia memiliki beban yang besar. Rencana pemerintah untuk tahun 2019 akan mengeluarkan anggaran untuk pembuatan administratif dan penambahan materi pembelajaran yang akan digunakan. Kurang lebih sebesar 11,4 $\%$ akan dilakukan penambahan anggaran dari tahun 2018 (detikNews, 2019). Peningkatan Pendidikan juga dilakukan dan ditunjukkan dengan peningkatan SDM yaitu guru, fasilitas belajar dan infrastruktur, bukan hanya sekolah yang berada di pusat kota tapi juga di daerah. Untuk Pendidikan di daerah, pemerintah diharapkan dapat lebih memperhatikan untuk pemerataan mutu Pendidikan di Indonesia.

Pendidikan di Indonesia kian hari semakin memprihatinkan. Pemeringkatan yang dilakukan di ASEAN melalui Education Index yang dikeluarkan oleh Human Development Reports, Indonesia berada di posisi ke tujuh dengan nilai skor 0,622. Selain itu, data dari The Global Talent
Competitiveness Index (GTCI) pada tahun 2019 Indonesia menduduki urutan ke 67 dari 125, SDM di Indonesia belum memiliki daya saing yang baik dibandingkan dengan negara lain.

Kemampuan yang dimiliki oleh setiap guru tidak merata sehingga hal ini dapat membuat pengetahuan yang akan diterima oleh setiap siswa menjadi tidak sama antara yang satu dan lainnya. Belum lagi, guru yang berada di luar pulau Jawa, termasuk kesulitan dengan area yang ditempati. Area mereka memiliki jarak yang jauh dan fasilitas yang belum memadai. Perubahan yang dilakukan dalam kurikulum sering kali tidak melibatkan pendidik karena hanya dilakukan di level pemilik kebijakan sehingga membuat para guru kesulitan dalam mengimplementasikannya. Selain itu, diharapkan juga peranan dari orang tua dalam hal pendampingan untuk membantu setiap siswa dalam belajar (Kompas.com, 2019).

\section{KAJIAN LITERATUR Kinerja}

Kinerja seorang guru merupakan sebuah hal yang amat penting untuk meningkatkan kualitas Pendidikan yang nantinya akan mengasilkan SDM unggul untuk Indonesia. Kinerja merupakan sebuah pencapaian dari seseorang dan hasilnya diakui oleh perusahaan yang diambil dari kemampuan, sifat dan usaha sebagai bagian dari pekerjaan karyawan (Ling \& Bhatti, 2014).

\section{Motivasi}

Motivasi yang diawali dengan kata motif yang berarti sebuah keinginan. Sehingga motivasi menurut Chaudhary, N., \& Sharma (2012) dapat diartikan sebagai proses organisasi dapat mengapresiasi karyawan dengan bentuk penghargaan, dsb untuk mencapai tujuan dari organisasi. Menurut Zameer et al. (2014) motivasi merupakan peran yang sangat penting dalam organisasi. Apabila karyawan tidak termotivasi maka organisasi akan sulit untuk mencapai tujuan yang diinginkan 


\section{Dukungan Sosial}

Dukungan dari sosial menurut kebiasaannya menunjukkan hasil yang positif ataupun campuran (Nurullah, 2012). Harga diri seseorang dapat meningkat merupakan elemen penting pada variabel ini. Menurut (Ling \& Bhatti, 2014) dukungan sosial secara signifikan berpengaruh terhadap kinerja. Apabila dukungan sosial yang diterima baik saat di tempat kerja maka secara signifikan peningkatan terhadap kinerja juga terjadi.

\section{Kepuasan Kerja}

Kepuasan kerja merupakan sebuah sikap yang menunjukan perilaku seseorang secara psikologis (Chen, X. H., Zhao, K., Liu, X. $\& \mathrm{Wu}, 2012)$. Variabel ini merupakan hal menakutkan bagi seorang manajer untuk proses pengelolaan SDM pada sebuah organisasi. Selain itu, menurut Aziri (2011), I. Dugguh \& Dennis (2014), Raza, Jawaid, \& Hassan (2015) kepuasan dari karyawan berpengaruh terhadap kinerja dari karyawan. Namun ada juga penelitian yang memiliki hasil bahwa kepuasan belum tentu berpengaruh terhadap kinerja (Ahmad, Ahmad, \& Ali Shah, 2010).

\section{Sikap}

Sikap adalah hal yang menunjukkan perilaku seorang karyawan, bagaimana seseorang dapat memahami dan melakukan peningkatan sikap sangat penting bagi organisasi. Inuwa (2015) menerangkan bahwa sikap merupakan perilaku seseorang dalam menghadapi pekerjaan serta komitmen dan keterlibatan seseorang tersebut pada organisasi. Hasil studi yang menunjukkan bahwa sikap memiliki pengaruh terhadap kinerja dikemukakan oleh Ahmad, Ahmad, \& Ali Shah (2010), selain itu ada juga penelitian oleh Susanty, Miradipta, \& Jie (2013).

\section{Manajemen Pengetahuan}

Manajemen pengetahuan merupakan hal strategis untuk proses pengembangan organisasi serta dapat memberikan competitive advantage secara berlanjut bagi sebuah organisasi (Masa'deh, Shannak, Maqableh, \& Tarhini, 2017). Hubungan yang baik terbangun antara organisasi dan SDM hingga pada hubungan kepada masyarakat terlihat dari kinerja yang mana sebagai faktor yang dapat menunjukkan seorang karyawan dapat memahami dengan sangat efektif dan benar proses tersebut. Kinerja manajemen pengetahuan memiliki hasil pengaruh yang positif karena dipercaya apabila dengan melakukan proses bertukar informasi bersama dengan kolega akan meningkatkan keinginan untuk melakukan kolaborasi serta meluaskan pengetahuan dan mampu untuk melakukan pemecahan masalah serta meningkatnya kinerja (Masa'deh et al., 2017).

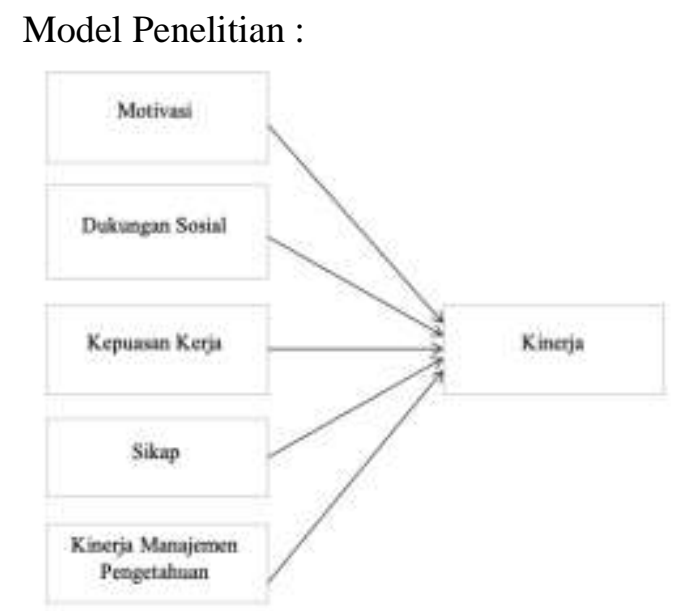

Sumber: (Ling \& Bhatti, 2014), (Shahzadi, 2014), (Masa'deh et al., 2017), (Inuwa, 2015).

Gambar 1. Model Penelitian

\section{METODE PENELITIAN}

Data Global Talent Competitiveness Index pada tahun 2019, Indonesia menduduki urutan 67 dari 125 negara yang turut serta. Sehingga terlihat bahwa pendidikan Indonesia masih perlu peningkatan yang signifikan untuk peningkatan SDM unggul yang saat ini sedang dicanangkan oleh pemerintah. Pada penelitian ini menggunakan pengukuran angka dengan data analisis dengan pengujian statistik (Indriantoro, Nur, 2014).

Guru sekolah menegah atas (SMA dan SMK) yang ada di Kota Batam adalah objek penelitian di dalam penelitian ini. 1.121 guru SMA dan 1.190 guru SMK yang 
berada di Kota Batam menjadi target penulis. Sedangkan sampel yang penulis gunakan merupakan guru SMA dan SMK di Kota Batam dengan total 375 kuesioner yang akan disebarkan kepada 18 SMA dan SMK yang berada di Kota Batam. Sampel ini didapatkan dari proses perhitungan slovin dengan rumus :

$n=\mathrm{N} /\left(1+\left(\mathrm{N} \mathrm{x} e^{2}\right)\right)$

Sumber : (Sarwono, 2016)

Pengumpulan data dilakukan secara langsung oleh penulis melalui kuesioner dengan meminta responden tersebut mengisi jawaban yang telah tersedia pada kuesioner (Indriantoro, Nur, 2014). Analisis data dilakukan dengan analisis deskriptif yaitu dengan melakukan pengujian data dengan menyajikan tabulasi data secara numerik dan grafik. Analisis ini diukur dengan menunjukkan nilai sentral pada pendistribusian data yang diukur dalam mean, median dan standar deviasi. Uji T juga dilakukan pada penelitian ini untuk mengetahui pengaruh dari variabel independen secara menyeluruh. Dianggap siginifikan jika memiliki nilai kurang dari 0.05 dan jika lebih dari 0.05 maka data dihasilkan dianggap tidak ditemukan (Sujarweni, 2018). Uji F juga dilakukan pada penelitian ini, menurut (Sujarweni, 2018) pengujian ini memiliki nilai signifikan besar dari 0.05 maka variabel independen tidak memiliki pengaruh secara signifikan dan jika hasil kurang dari 0.05 maka variabel independen dinyatakan memiliki pengaruh signifikan terhadap dependen.

Penelitian ini menguji 5 variabel independen dan 1 variabel dependen dan semua variable ini diukur dengan skala likert lima poin. Skala likert lima poin merupakan data interval, dimana data interval merupakan kategori data metric (Sekaran, Uma, \& Bougie, 2017). Pada variabel motivasi pertanyaan diadopsi dan diukur dengan menggunakan 6 pertanyaan yang diadopsi dan dikembangkan (Latif,
Mushtaq, Muhammad, Ferdoos, \& Hummayoun, 2013). Variabel dukungan sosial menggunakan 3 pertanyaan (Chang $\& \mathrm{Wu}, 2013)$. Variabel kepuasan kerja mengadopsi dan dilakukan pengembangan untuk pertanyaan, sebanyak 5 pertanyaan diadopsi dari penelitian Susanty et al. (2013). Variabel sikap mengukur 11 pertanyaan yang diadopsi dan dikembangkan dari (Muda, Rafiki, \& Harahap, 2014). Variabel kinerja manajemen pengetahuan mengukur 10 pertanyaan yang diadopsi dan dikembangkan (Masa'deh et al., 2017).

\section{PEMBAHASAN}

Subjek penelitian ini adalah guru sekolah menengah terhadap 16 sekolah negeri dan swasta di Kota Batam. Dalam proses penyebaran tidak seluruhnya berjalan sesuai harapan, terdapat 3 penolakan dari pihak sekolah dan Yayasan. Akhirnya, dari total yang disebarkan sebanyak 375 kuesioner, hanya 341 yang berhasil terisi. Karena dengan dilakukan proses menunggu pengisian maka kuesioner dapat dipastikan proses selesai dan mendeteksi kesalahan pengisian dan dilakukan pengisian ulang. Selain itu, juga kuesioner tersebut dititipkan kepada guru yang dikenal oleh peneliti sehingga dapat dipastikan bahawa kuesioner tersebut kembali dengan pengisian lengkap.

Tabel 1

Hasil Penyebaran Kuesioner

\begin{tabular}{|l|c|}
\hline \multicolumn{1}{|c|}{$\begin{array}{c}\text { Keterangan } \\
\text { Penyebaran }\end{array}$} & $\begin{array}{c}\text { Jumlah } \\
\text { Responden }\end{array}$ \\
\hline Penyebaran & 375 \\
\hline Tidak kembali & 30 \\
\hline Tidak Lengkap & 4 \\
\hline Layak Uji & 341 \\
\hline
\end{tabular}

Sumber : Data diolah

Terdapat 397 orang guru SMA yang berjenis kelamin pria dan 724 yang berjenis kelamin wanita, 543 orang guru SMK yang berjenis kelamin pria dan 647 orang guru berjenis kelamin wanita, ini merupakan data yang didapatkan pada tahun 2017/2018 
dari Dapo Dikdasmen Kemendikbud Kota Batam sehingga dapat disimpulkan bahwa pada penelitian ini lebih banyak guru wanita yang melakukan pengisian kuesioner.

Tabel 2

Responden Berdasarkan Jenis Kelamin

\begin{tabular}{|l|c|c|}
\hline $\begin{array}{c}\text { Jenis } \\
\text { Kelamin }\end{array}$ & $\begin{array}{c}\text { Jumlah } \\
\text { Responden }\end{array}$ & Persentase \\
\hline Pria & 93 & $27,27 \%$ \\
\hline Wanita & 248 & $72,73 \%$ \\
\hline Jumlah & 341 & $100,00 \%$ \\
\hline
\end{tabular}

Sumber : Data diolah

Responden memiliki masa kerja paling banyak adalah $0-10$ tahun dengan usia 22 - 50 tahun sehingga memiliki tingkat pemahaman dalam penginterpretasian yang baik dalam menjelaskan pernyataan kuesioner.

Tabel 3

Masa Kerja Responden

\begin{tabular}{|l|c|c|}
\hline Masa Kerja & $\begin{array}{c}\text { Jumlah } \\
\text { Responden }\end{array}$ & Persentase \\
\hline $0-10$ tahun & 197 & $57,77 \%$ \\
\hline $11-20$ tahun & 107 & $31,38 \%$ \\
\hline 21-30 tahun & 27 & $7,92 \%$ \\
\hline$>30$ tahun & 10 & $2,93 \%$ \\
\hline Jumlah & 341 & $100 \%$ \\
\hline
\end{tabular}

Sumber : Data diolah

Data yang didapatkan dari data statistik Kemendikbud bahwa berdasarkan Pendidikan dari setiap guru sebanyak 1,448 guru dengan Pendidikan sarjana dan 11,147 memiliki Pendidikan pascasarjana. Oleh sebab itu, responden guru yang paling banyak mengisi adalah dengan Pendidikan sarjana.

Tabel 4

Pendidikan Responden

\begin{tabular}{|l|c|c|}
\hline \multicolumn{1}{|c|}{ Pendidikan } & hlah Responden & Persentase \\
\hline Strata II & 15 & $4,40 \%$ \\
\hline $\begin{array}{l}\text { Sarjana } \\
\text { /Diploma IV }\end{array}$ & 316 & $92,67 \%$ \\
\hline Diploma III & 2 & $0,59 \%$ \\
\hline SMA/K & 8 & $2,35 \%$ \\
\hline Jumlah & 341 & $100,00 \%$ \\
\hline
\end{tabular}

Sumber : Data diolah
Hasil pengujian $\mathrm{T}$ dilakukan untuk menguji variabel motivasi, hasil menunjukkan terdapat hubungan signifikansi antar variabel motivasi terhadap kinerja karena memiliki nilai 0,00 lebih kecil dari 0,05, sehingga sesuai dengan hipotesis pada penelitian ini dapat ditarik kesimpulan bahwa terdapat pengaruh positif pada variabel motivasi dan kinerja. Pengaruh positif dapat dilihat dari bagaimana setiap guru merasa termotivasi untuk melakukan pekerjaan dnegan baik dan selalu memikirkan solusi untuk penyelesaian pekerjaan seara cepat untuk pengefektifan pekerjaan. Hasil ini sejalan dengan penelitian dari Muda et al. (2014), (Zameer et al. (2014), Shahzadi (2014), Omolo (2015) dan Omolo (2015).

Hasil pengujian dari variabel dukungan sosial terhadap kinerja memilik hasil tidak signifikan karena nila sig $>0,05$ yaitu 0,47 , maka dari itu dukungan sosial secara signifikan tidak memiliki pengaruh terhadap kinerja. Tidak signifikan dikarenakan saat di sekolah guru hanya bertugas mengajar tanpa ada kegiatan bertemu dengan rekan baru sehingga hal ini dirasa begitu monoton dan guru menjadi tidak dapat membangun hubungan dengan orang lain dalam bidang ini. Namun hasil ini berbeda dengan penelitian yang telah dilakukan sebelumnya oleh Ahmad, (2015), Chang \& Wu (2013), Shahzadi (2014), Ling \& Bhatti (2014) dan Chan (2015).

Variabel kepuasan kerja terhadap kinerja memiliki hasil pengujian nilai signifikan 0,00, lebih kecil dari 0,05 maka dapat disimpulkan hasil hipotesis terbukti, bahwa adanya pengaruh signifikan antara kepuasan kerja terhadap kinerja. Kepuasan yang dirasakan oleh guru dilihat dari setiap pekerjaan yang mereka kerjakan, jenis pekerjaan menurut mereka sesuai dengan kapasitasnya, dan mereka tidak pernah berfikir untuk keluar dari pekerjaan ini. Namun hasil ini berbeda dengan penelitian yang sebelumnya telah dilakukan oleh Ahmad et al. (2010). Menurut Ahmad et al. (2010) kepuasan tidak memiliki pengaruh dengan kinerja, hal ini disebabkan oleh setiap orang memiliki pandangan bahwa apa yang dikerjakan oleh masing-masing 
individu sudah baik dari orang lain sehingga mereka mengharapkan dapat diberikan tambahan penghasilan atas apa yang telah mereka kerjakan.

Hasil pengujian dari variabel sikap dan kinerja memiliki nilai signifikan 0,00 dan hasil ini lebih kecil dari 0,05. Hasil ini terbukti memiliki hasil signifikan positif yang dikarenakan bahwa setiap guru telah bekerja dengan sangat keras dan giat maka akan membawa mereka pada produktivitas yang tinggi serta mereka memilih untuk tanggungjawab terhadap pekerjaan yang sangat besar terhadap pekerjaan daripada pekerjaan yang kecil. Hasil ini juga sejalan dengan penelitian Ahmad et al. (2010), Susanty et al. (2013).

Hasil pengujian kinerja manajemen pengetahuan terhadap kinerja memiliki nilai signifikan 0,00 lebih kecil dari 0,05. Dengan hasil tersebut memiliki arti bahwa hipotesis terbukti secara signifikan memiliki pengaruh positif antara kinerja manajemen pengetahuan dan kinerja dikarenakan setiap guru selalu mau untuk menerima ilmu baru yang berasal dari tempat mereka bekerja dan bahwa dengan adanya kegiatan berbagi pengetahuan sesama rekan guru lainnya dapat diandalkan, mudah dipahami serta relevan dengan pekerjaan yang sedang dijalankan. Hasil ini juga menunjukan hasil yang sama dengan penelitian sebelumnya oleh Obeidat, Masa'deh, \& Abdallah (2014), Masa'deh et al. (2017).

Tabel 5

Berdasarkan Pengujian Koefisien Determinasi

\begin{tabular}{|c|c|c|}
\hline Variabel & R Square & Adjusted $\boldsymbol{R}^{2}$ \\
\hline Kinerja & 0,24 & 0,23 \\
\hline
\end{tabular}

Sumber : Data diolah

Motivasi, kepuasan kerja, dukungan sosial, sikap dan kinerja manajemen pengetahuan dengan hasil uji koefisien determinasi menunjukkan hasil 23\% yang artinya dapat memprediksi kinerja dari seorang guru, sedangkan variabel keadilan, ekuitas (Inuwa, 2015), penghargaan non finansial, penghargaan finansial dan pelatihan (Kenyatta, 2015) jam kerja, stres, hambatan komunikasi (Iqbal, Ijaz, Latif, \& Mushtaq, 2015) merupakan faktor lainnya yang berasal dari luar model penelitian ini dengan hasil $77 \%$.

\section{PENUTUP}

Tujuan dari dilakukannya penelitian ini adalah untuk menemukan jawaban apakah motivasi, dukungan sosial, kepuasan kerja, sikap dan kinerja manajemen pengetahuan memiliki pengaruh yang signifikan terhadap kinerja guru SMA dan SMK di Kota Batam. Dari 5 (lima) variabel yang diuji, yaitu motivasi, dukungan sosial, kepuasan kerja, sikap dan kinerja manajemen pengetahuan terhadap Kinerja menunjukan hasil bahwa 4 (empat) variabel memiliki nilai signifikan sedangkan 1 (satu) variabel memiliki nilai tidak signifikan terhadap variabel kinerja.

Variabel dukungan sosial tidak berpengaruh signifikan dikarenakan hubungan bersosialisasi dari setiap guru terhadap orang lain masih kurang, mereka kurang bertemu dengan orang di luar lingkungan mereka sehingga itu dirasa menjadi hal yang monoton.

Terdapat keterbatasan pada penelitian ini yaitu, belum ada pengujian kinerja yang berdasarkan dengan gender, apakah gender dapat mempengaruhi kinerja seorang guru seperti penelitian yang di kemukakan oleh Shahzadi (2014). Selain itu juga masih terdapat beberapa penolakan dari pihak sekolah tanpa alasan yang jelas dan tanpa keterangan. Serta masih terdapat banyak faktor lain yang mungkin dapat diuji terhadap kinerja.

Dari hasil yang telah didapatkan diharapkan ada perhatian dari pihak sekolah terhadap kinerja guru. Untuk variabel motivasi diharapkan pihak sekolah dapat selalu memberikan lingkungan kerja yang kondusif dan nyaman serta dapat selalu mendukung upaya yang dilakukan setiap guru untuk pengembangan ilmu dan pembelajaran. Untuk kepuasan kerja dari setiap guru menjadi hal penting yang harus 
dipertimbangkan oleh setiap sekolah, dianjurkan ada pemeriksaan yang tersktruktur agar tidak terjadi ketidakpuasan guru dalam menjalankan tugas ataupun terkait dengan hal lainnya. Untuk variabel sikap, Kepala Sekolah diharapkan dapat merancang kegiatan atau mengikutsertakan guru dalam kegiatan misalnya sertifikasi yang terstruktur dan dapat dimasukkan ke dalam program kerja sekolah sehingga menjadi terjadawal agar setiap guru dapat mempelajari hal baru. Untuk variabel kinerja manajemen pengetahuan diharapkan seolah dapat menampung ide baru dari para guru dan dapat menyalurkan kembali kepada guru lainnya untuk dapat terjadinya pertukaran informasi di dalam lingkungan sekolah. Hal ini dapat membuat lingkungan baru dimana setiap guru dapat mencari dan mengembangkan ide baru yang dapat membantu pekerjaan mereka.

Bagi setiap guru diharapkan dapat terus melakukan pembaharuan pembelajaran dan cara mengajar agar dirasa tidak membosankan oleh siswa, harus mengikuti perkembangan saat ini dimana menggunakan bantuan media yang diharapkan akan terus dapat meningkatkan motivasi serta produktivitas guru dalam pengajaran.

\section{REFERENSI}

Ahmad, H., Ahmad, K., \& Ali Shah, I. (2010). Relationship between Job Satisfaction, Job Performance Attitude towards Work and Organizational Commitment. European Journal of Social Sciences, 18(2), 257-267.

Allen, M. A. M. (2015). Employee Relations: The International Journal Article information: Employee Relations, 37(5), 1-37.

Aziri, B. (2011). Job Satisfaction: A Literature Review. Management Research and Practice, 3(4), 77-86.

Chan, A. N. W. (2015). Social support for improved work integration. Social Enterprise Journal, 11(1), 47-68. https://doi.org/10.1108/sej-07-20140033

Chang, C. C., \& Wu, C. C. (2013).
Multilevel analysis of work context and social support climate in libraries. Aslib Proceedings: New Information Perspectives, 65(6), 644-658. https://doi.org/10.1108/AP-05-20120051

Chaudhary, N., \& Sharma, B. (2012). Impact of employee motivation on performance (productivity) in private organization. International Journal of Business Trends and Technology, 2(4).

Chen, X. H., Zhao, K., Liu, X. \& Wu, D. D. (2012). Improving employees job satisfaction and innovation performance using conflict management. International Journal of Conflict Management, 23(2), 151172.

https://doi.org/10.1108/104440612112 18276

detikNews. (2019). Potret Pendidikan Indonesia di Tengah Perkembangan Teknologi. Retrieved from detikNews website: https://news.detik.com/dw/d4533564/potret-pendidikan-indonesiadi-tengah-perkembangan-teknologi

GTCI. (2019). The Global Competitiveness Report 2019. Retrieved from http://www3.weforum.org/docs/WEF TheGlobalCompetitivenessReport201 9.pdf

I. Dugguh, S., \& Dennis, A. (2014). Job satisfaction theories: Traceability to employee performance in organizations. IOSR Journal of Business and Management, 16(5), 1118. https://doi.org/10.9790/487x16511118

Indriantoro, Nur, dan B. S. (2014). Metodologi Penelitian Bisnis Untuk Akuntansi \& Manajemen (1st ed.). Yogyakarta: Yogyakarta: BPFE Yogyakarta.

Inuwa, M. (2015). The International Journal Of Business \& Management The Impact of Employee Engagement in Improving Performance Abstract: The International Journal Of Business \& Management, 3(2), 111-114.

Iqbal, A., Ijaz, M., Latif, F., \& Mushtaq, H. 
(2015). Factors Affecting the Employees Performance: a Case Study of Banking Sector in Pakistan. European Journal of Business and Social Sciences, 4(08), 309-318. Retrieved from http://www.ejbss.com/recent.aspx-/

Kenyatta, J. (2015). The Effects of Motivation on Job Performance A Case Study of KCB Coast Region Belly Onanda. International Journal of Scientific and Research Publications, 5(9), 1-13. Retrieved from www.ijsrp.org

Kompas.com. (2019). Ini 11 Pesan Guru Nusantara untuk Pendidikan Indonesia. Retrieved from Kompas.com website: https://edukasi.kompas.com/read/2019 /10/27/18051621/mas-nadiem-ini-11pesan-guru-nusantara-untukpendidikan-indonesia?page $=$ all

Latif, M. S., Mushtaq, A., Muhammad, Q., Ferdoos, A., \& Hummayoun, N. (2013). Impact of employee' s job satisfaction on organizational performance . European Journal of Business and Management, 5(5), 166171.

Ling, S., \& Bhatti, M. (2014). Work Stress and Job Performance in Malaysia Academic Sector: Role of Social Support as Moderator. British Journal of Economics, Management \& Trade, 4(12), 1986-1998. https://doi.org/10.9734/bjemt/2014/12 098

Masa'deh, R., Shannak, R., Maqableh, M., \& Tarhini, A. (2017). The impact of knowledge management on job performance in higher education: The case of the University of Jordan. Journal of Enterprise Information Management, 30(2), 244-262. https://doi.org/10.1108/JEIM-092015-0087

Muda, I., Rafiki, A., \& Harahap, M. R. (2014). Factors Influencing Employees 'Performance: A Study on the Islamic Banks in Indonesia.
International Journal of Business and Social Sience, 5(2), 73-80.

Nurullah, A. S. (2012). Received and Provided Social Support: A Review ofCurrent Evidence and Future Directions. Journal of Psychosomatic Research, 27(3), 173-188.

Obeidat, B., Masa'deh, R., \& Abdallah, A. (2014). The relationships among human resource management practices, organizational commitment, and knowledge management processes: a structural equation modeling approach. International Journal of Business and Management, 9(3), 9-26.

Omolo, P. A. (2015). Effect of motivation on employee performance of commercial banks in Kenya: A case study of Kenya Commercial Bank in Migori County. International Journal of Human Resource Studies, 5(2), 87. https://doi.org/10.5296/ijhrs.v5i2.7504

Raza, S. A., Jawaid, S. T., \& Hassan, A. (2015). Internet banking and customer satisfaction in Pakistan. Qualitative Research in Financial Markets, 7(1), 24-36.

https://doi.org/10.1108/QRFM-092013-0027

Sarwono, J. (2016). No Title العقد الفريد. In Metode Penelitian Kuantitatif dan Kualitatif (1st ed., p. 400). Yogyakarta: Graha Ilmu.

Sekaran, Uma, \& Bougie, R. (2017). Metode Penelitian untuk Bisnis: Pendekatan Pengembangan-Keahlian (6th ed.). Jakarta Selatan: Salemba Empat.

Shahzadi, I. et al. (2014). Impact of Employee Motivation on Work Performance. International Journal of Scientific and Research Publications (IJSRP), 8(3), 159-167. https://doi.org/10.29322/ijsrp.8.3.2018 .p7544

Sujarweni, V. W. (2018). Metodologi Penelitian Bisnis dan Ekonomi Pendekatan Kuantitatif. Pustaka Baru Press. 
Susanty, A., Miradipta, R., \& Jie, F. (2013). Analysis of the Effect of Attitude Toward Works, Organizational Commitment, and Job Satisfaction. European Journal of Business and Social Sciences, 1(10), 15-24.

Zameer, H., Alireza, S., Nisar, W., \& Amir, M. (2014). The Impact of the Motivation on the Employees Performance in Beverage Industry of Pakistan. International Journal of Academic Research in Accounting, Finance and Management Sciences, 4(1), 293-298. https://doi.org/10.6007/ijarafms/v4i1 $1 / 630$

\section{BIODATA PENULIS}

Dame Afrina Sihombing merupakan Dosen di Universitas Internasional Batam. Memiliki Pendidikan Sarjana Akuntansi di Universitas Pancasila, lulus pada tahun 2013 dan Pendidikan Magister Manajemen di Universitas Internasional Batam, lulus pada tahun 2018. 